Conclusion: Even though management goal is directed at remission induction in the earliest stages of rheumatoid arthritis with molecular targeted therapies in most of the developed countries, in rural parts of the developing countries low rate of adherence to follow-up appointments and medications is still an important difficulty in management. Patients receiving biologic DMARDs have higher adherence to treatment. Awareness and education of patients in rheumatoid arthritis, as well as in all chronic diseases, is most important aspect of management.

Disclosure of Interests: None declared

DOI: 10.1136/annrheumdis-2019-eular.6393

\section{AB0351 ELDERLY-ONSET RHEUMATOID ARTHRITIS (EORA): DIFFERENCES ACCORDING TO CLINICAL DEBUT AND SEROLOGICAL POSITIVITY}

María Andreína Terán Tinedo, Cristina Pijoan Moratalla, Jose Renato Quiñones Torres. Hospital Universitario Ramón y Cajal, Madrid, Spain

Background: In patients with Elderly-onset Rheumatoid Arthritis (EORA) has been described a clinical debut mimicking polymyalgia rheumatica with rhizomelic pseudopolyarthritis, in contrast with the classical profile of patients with Rheumatoid Arthritis similar to younger patients. We compare in our study these two profiles of the disease.

Objectives: To describe and compare the differences according to clinical debut, serological positivity and its implications in terms of treatment and prognostic factors in patients with Elderly-onset Rheumatoid Arthritis (EORA).

Methods: Patients with a diagnosis of RA over 65 years of age according to ACR/EULAR 2010 criteria were included. A database was created including the age of onset, the presence of polymyalgia-like symptoms (rhizomelic pseudopolyarthritis), the positivity of rheumatoid factor (RF) and anti-citrullinated protein antibodies (ACPAs), elevation of acute phase reactants (APR), the presence of erosions and the treatment required. Finally, data was analyzed according to clinical debut, serological positivity and prognostic factors.

Results: 83 patients diagnosed of EORA were included, with an average age of 73.8 years. $71.25 \%$ had positive RF $(58.75 \%$ high titers) and $62.5 \%$ had positive ACPA (52.3\% high titers). $24 / 83$ patients (29\%) debuted with a polymyalgia-like symptoms. $47.5 \%$ had persistent APR elevation during follow-up. Regarding treatment, $15 \%$ were treated only with corticosteroids, $81.5 \%$ required treatment with DMARDs and $15 \%$ were receiving biological treatment. $42 / 83$ patients $(50 \%)$ had erosions on plain X-rays. Of those patients with a polymyalgia-like profile, $52.2 \%$ (43/83) had positive RF but most of them had low titers (61\%). On the other hand, patients without polymyalgia-like symptoms had positive RF in $78 \%$ of the cases and most of them at high titers $(66 \%, p=0.01)$. In the first group there was less positivity for ACPAs $(26 \%, p=$ 0.00004 ) and half of them had low titers. Erosions were observed in only $30 \%$ of the patients with polymyalgia-like symptoms, while those without this profile had more erosions $(58 \%, p=0.02)$ and higher APR $(50 \%, p=0.026)$. Regarding treatment, in the group with polymyalgialike symptoms only $34 \%$ were treated with corticosteroids, $65 \%$ required DMARDs and no patients had received biological treatment, whereas in the non-polymyalgic group, $88 \%$ required DMARDs and $21 \%$ required biologics ( $p=0.01$ for both results). Analyzing patients with positive RF and ACPAs at high titers, $93 \%$ received treatment with DMARDs and $24 \%$ required biological treatment. $65 \%$ had persistent elevation of APR and $48 \%$ presented erosions on plain X- rays. Only 2 patients with positive RF and ACPAs at high titers debuted with a polymyalgia-like symptoms.

Conclusion: Patients with EORA with polymyalgia-like symptoms tend to have less erosions and a higher prevalence of negative RF and ACPA or at low titers. These patients usually require less DMARDs and biological treatments to control the disease unlike patients with non-polymyalgia symptoms. On the other hand, patients with high RF and ACPA titers have more erosions and elevated APR during follow-up but do not usually experience polymyalgia-like symptoms.

\section{REFERENCE}

[1] Tutuncu Z, Reed G, Kremer J, Kavanaugh A. Do patients with older-onset rheumatoid arthritis receive less aggressive treatment?. Ann Rheum Dis. 2006;65(9):1226-9.

Disclosure of Interests: None declared

DOI: 10.1136/annrheumdis-2019-eular.7682

\section{$\mathrm{AB} 0352$ \\ HIGH PREVALENCE OF ANTICIPATORY AND ASSOCIATIVE SYMPTOMS OF METHOTREXATE INTOLERANCE IN PATIENTS WITH RHEUMATOID ARTHRITIS}

Rawdha Tekaya, Wafa Triki, Aicha Ben Tekaya, Olfa Saidane, Ines Mahmoud, Leila Abdelmoula, R.Tekaya, W. Triki, A. Ben Tekaya, Oo.Saidane, I.Mahmoud, L. Abdelmoula. Charles Nicolle Hospital, Rheumatology, Tunis, Tunisia

Background: Methotrexate (MTX) is the most widely used anti-rheumatic drug in the treatment of Rheumatoid Arthritis (RA) due to low costs, efficacy and an acceptable safety profile. However MTX has certain side effects. The most common side effects include the gastrointestinal tract not only after taking MTX, but also before MTX intake (anticipatory) and when thinking of MTX (associative).

Objectives: The aim of this study was to assess the prevalence of MTX intolerance and particularly the anticipatory and associative symptoms using the validated methotrexate intolerance Severity Score (MISS) (1) Methods: We performed a cross-sectional descriptive study that involved patients with RA and treated by MTX for more than 3 months, compiled from Charles Nicolle hospital's rheumatologic department. The tolerance of MTX was assessed by the MISS questionnaire. The MISS Questionnaire includes five elements: abdominal pain, nausea, vomiting, fatigue, and behavioral symptoms of restlessness, crying, irritability and drug refusal. Each symptom is evaluated after intake of MTX, before taking MTX (anticipatory) and on thinking about MTX (associative). MTX intolerance was defined as $\geq 6$ points on the MISS, with at least 1 point on anticipatory, associative or behavioral adverse effects.

Results: A total of 100 RA patients (87 women and 13 men) with a mean age of 53,5 years. The MTX was administrated by oral route in $91 \%$ of patients; the other $9 \%$ received it by intramuscular way. The average MTX weekly dose was $15,4 \mathrm{mg}$. The average MTX duration was 76,7 months. All patients received folic acid with an average of $7,6 \mathrm{mg}$ a week. MTX intolerance was found in $36 \%$ of patients. Abdominal pain was the most common symptom occurring in $55 \%$ of patients and up to $91.66 \%$ in MTX-intolerant patients, followed by nausea in $51 \%$ of patients and in $86.11 \%$ of MTX-intolerant patients and vomiting in $16 \%$ of patients and in $44.44 \%$ of MTX intolerant-patients. Anticipatory and associative abdominal pain affected $72,2 \%$ and 69,4 of intolerant-patients respectively. Anticipatory and associative nausea were found in $58,3 \%$ and $59 \%$ of intolerant-patients respectively. Anticipatory vomiting occurred in $16.6 \%$ of intolerant-patients. Overall, behavioral symptoms occurred in $75 \%$ of intolerant-patients, of whom $19.4 \%$ refused MTX. Older age was significantly correlated with better tolerance to MTX $(p=0,02)$. There was no correlation between the dose of MTX, the duration of MTX intake and the route of MTX and the MISS score (respectively $p=0,7, p=0,07$ and $p=0,2$ ). Also, the use of other disease modifying drugs didn't worsen the tolerance of MTX.

Conclusion: To conclude intolerance to MTX is frequently seen in RA. In addition to gastrointestinal symptoms after taking MTX. RA patients can suffer from anticipatory and associative gastrointestinal symptoms. We should screen these symptoms earlier using MISS questionnaire in order to improve MTX compliance.

\section{REFERENCE}

[1] Bulatovic M, Heijstek MW, Verkaaik M, van Dijkhuizen EH, Armbrust W, Hoppenreijs EP, et al. High prevalence of methotrexate intolerance in juvenile idiopathic arthritis: development and validation of a methotrexate intolerance severity score. Arthritis and rheumatism. 2011;63(7):2007-13.

Acknowledgement: None

Disclosure of Interests: None declared

DOI: 10.1136/annrheumdis-2019-eular.5004

\section{AB0353 WORSE OFFICE AND 24-HOUR BRACHIAL AND CENTRAL AORTIC BLOOD PRESSURE MONITORING PROFILE IN PATIENTS WITH RHEUMATOID ARTHRITIS COMPARED TO CONTROLS}

Elena Troitskaya ${ }^{1}$, Sergei Velmakin ${ }^{1}$, Svetlana Villevalde ${ }^{2}$, Zhanna Kobalava ${ }^{3}$. ${ }^{1}$ Peoples' Friendship University of Russia (RUDN University), Internal diseases, Moscow, Russian Federation; ${ }^{2}$ Almazov National Medical Research Centre, St. Petersburg, Russian Federation; ${ }^{3}$ Peoples' Friendship University of Russia (RUDN University), Moscow, Russian Federation

Background: Hypertension (HTN) contributes to increased cardio-vascular (CV) morbidity and mortality in RA. Recent European guidelines on the management of HTN encourage wider use of ambulatory blood pressure 